\title{
Fungi, Biodeterioration and Cultural Heritage
}

\author{
Bassols AC and Bassols K \\ Hospital Angeles del Carmen, Mexico \\ Faculty of Sciences UNAM, Ciudad Universitaria, Mexico
}

*Corresponding author: Angel Carlos Bassols, Hospital Angeles del Carmen, Guadalajara,

\section{Mini Review}

Volume 3 Issue 1

Received Date: March 20, 2020

Published Date: March 31, 2020

DOI: $10.23880 /$ oajmms-16000119

Mexico, E mail: acbassols@gmail.com

\section{Mini Review}

There are multiple sources of biological pollution that can affect historical and modern buildings, museums, private art collections and even restoration studios. Microorganisms include archea, bacteria, and fungi, in fact rat or bird feces, pollen, lichens, several viruses, mites and even insect portion can contribute to biodegradation. In many cases even if the material or building is in appropriate conservation state, flooding, thunderstorms or ice accumulation can easily change that. Another risk factor is air conditioning either because it is not properly calibrated, due to failure or not having proper maintenance. Cultural patrimony is in constant risk of biodeterioration. The aim of this review is to give an overview of the microbiological decline of World Cultural Heritage in particular paper documents preserved in museums, archives and libraries [1-3].

Paper main component is cellulose, but there are several other elements and materials present in documents like ink and pigments. Fungi are among the dominant causes of paper biological degradation. There are two key mechanisms of microbiological decomposition: cellulose degradation and secondary metabolites synthesis [4].

Regular screening of books and documents is vital to locate and contain as much as possible fungal and bacterial establishment. Monitoring cultural heritage material means analyzing their surface but also examine air quality. Keeping the material free from biological decaying is not a matter of esthetics but a health concern. Library staff and visitors wellbeing depends on paper being properly cared. Some fungi can either act as human pathogens or cause allergies and long term toxic effects $[5,6]$.

There are several taxonomic genera associated with triggering rhinitis, rhinosinusitis, asthma, hypersensitivity pneumonitis or alveolitis. In particular, being in contact with
Staphylococcus sp., Aspergillus, Alternaria, Penicillium and Aureobasidium can produce intense reactions in humans. Unfortunately these genera are also the most frequent in libraries, archives and museums samples. Molecular analysis detected a wider microbiological community than previously thought. There have been found Chytridiomycota, Zygomycota (mainly opportunist), Basidiomycota in places with abundant wooden items and the most common fungi are Ascomycetes. Most of the fungi pollutants are found in dust and the microorganisms associated however there have been cases of cross contamination during bookmarking [6].

Advance paper decay induced by fungi interaction causes a diminished texture, with little or no mechanical capacity. Handling material in this state can promote further deterioration which can lead to losing documents and the information written on them. When fungi colonize some material, they can stimulate esthetic modifications because of the pigments they secrete. These pigments can either diminish the document legibility or decrease their artistic and monetary value; in extreme cases the object can be lost.

Ettanauer J, et al. [7] describes biological decomposition. This process is starts by biochemical processes, microbiological corrosion, solubilization and dissolution of the document ingredients. Given the variety of biological agents that can settle and stain the material that needs to be persevered there is a wide variety of biogenic pigments that can be found in paper. For example there are documents contaminated with chlorophyll, carotenes, phenols, anthraquinone and melanine resulting in different shades of color. Tints ranging from light yellow, orange and dark brown or even black can be found in cultural heritage documents. Ettanauer J, et al. [7] studied murals and ancient buildings from Central and Southern Europe. They used cultures and molecular techniques (DNA direct extraction, 16S ribosomal 


\section{Open Access Journal of Mycology \& Mycological Sciences}

PCR sequence and Denaturing Gradient Gel Electrophoresis) that helped them to recreate biological decline in their lab using the materials similar to the sited they studied. The NCBI database mentions three groups of bacterial phylla, Firmucetes $(89.7 \%$ of the isolated strains), Proteobacteria (6.9\%) and Actinobacteria (3.5\%).

Understanding if the fungal species found in paper are responsible of biodeterioration, or a byproduct of air pollution is vital to prevent further damage. Sequeira $S$, et al. [8] studied the association between specific fungal stains and the species that caused them. They processed the samples in situ with optic microscope and Scanning electron microscope. Their group compared the samples identification with molecular analyses. Sequeira et al., reach a correlation of 13 to $64 \%$ between the identified fungal structures and the cultures. The fungal grey/black and dark brown stains were associated with Chaetomium globosum, C. murorum, Penicillium chrysogenum, P. commune, Myxotrichum deflexum y Stachybotrys chartarum.

One of the best ways to prevent biological damage due to fungi and insects is keeping buildings closed. This is particularly important because insect caused destruction can take months or even years before it is damage beyond repair. However, fungi have amazingly quick rowing rates. In fact, a few days with high humidity can be enough to get biodegradation. Therefore, regular cleaning of cultural sites is extremely important. Each room and small places like cracks or dregs should be carefully cleaned to prevent insects. It is also very important to avoid litter or any edible material that could be found by moths and beetle. Fungi populations considerably decrease avoiding dust and any material carrying spores [9].

Fungal growth in museums strongly depends on indoor microclimatic conditions, the amount of available nutrients and how regularly the building is cleaned. Microclimatic conditions that promote fungal growth include: temperature, relative humidity, specific humidity.

If fungi reach paper, they are particularly problematic due to their ability to excrete cellulase. Two species that are frequently found in churches and heritage buildings are Serpula lacrymans and Conophora puteana. Both of them can be particularly aggressive if they reach wood altars and ceiling structures [10].

Sterflinger K, et al. [1] studied the hipomycetes more frequent in museums and art items. She mentions Alternaria sp., Aspergillus clavatus, A flavus, A glaucus, A. terreus, A. repens, A. ruber, A. fumigatus, A. ochraceus, A. nidulans, Aspergillus sect. Niger Botrytis cinerea, Chaetomium globosum, Chaetomium elatum, y C. indicu are presisten in fabrics containing cellulose or paper.

In ancient times, construction materials used for construction of buildings and museums include organic polymers like cellulose, starch, hemicellulose, pectin and lignin. All suitable substratum to promote fungi proliferation. Wooden items are particularly susceptible to colonization by Penicillium, Aspergillus, Aureobasidium, Trichoderma, Cladosporium, Chaetomium, Alternaria, Eurotium and Acremonium [11].

Integrating molecular studies, and mathematical models and biological cultures can improve the understanding of how fungi colonize and degrade cultural heritage. Baloccoa $C$, et al. [12] exceptional work focus on the effects of microenvironment in paper conservation. In particular, their experiments give tangible proof of how regulating air velocity, moisture and temperature can help to control fungi biodegradation. This information can improve the ability to better understand fungi pollution and help preserve paper antiques like books and parchment a very important part of cultural heritage.

There is some research centers equipped with light transmitter biosensors that could be very useful for medical, industrial, ecological and environmental purposes. These high tech machines have been used to study environmental pollution but have potential to be used in artwork. They can be used to determine if a specific microorganism is alive. The biosensors can accurately indicate if a treatment is working, which make better sampling for DNA [13].

Another interesting work is Palla F, et al. [14]. In their book Biotechnology and Conservation of Cultural Heritage, they describe in detail plant extracts used as biocides by the food, medical and pharmaceutical industries and they suggest, as another way to control microbial corrosion in cultural heritage.

One of the downsides of the current methods to control fungi is that they are extremely toxic and aggressive for the curator's skin. Phenols are an example of these substances and there are bacteria able to use them as carbon sources. Ordonez C, et al. [15] suggests a mixture of fluconazole with $20 \%$ water, $50 \%$ methanol and $30 \%$ ethanol as cosolvents. He found that after treating the material for 15 minutes there was a decrease of $90 \%$ of fungi colony-forming units.

The last study mentioned will be Cappitelli F, et al. [16]. They remind us, the constant effort human beings have made to preserve their documents. Their work reminds us all the different ways humankind have recorded their daily life and important documents. Papyrus, paper and modern magnetic and optic devices inevitably experience decaying (either 


\section{Open Access Journal of Mycology \& Mycological Sciences}

from chemical, physical or biological degradation).

In conclusion, the efforts to prevent biodeterioration of cultural heritage have been extensive. Some of the techniques have proven to be harmful for the staff in charge of preserving these documents. Fungi degradation is particularly aggressive and should be contained shortly after being detected. Cleaning regularly and controlling indoor microclimate are an efficient way to prevent fungi colonization. New methods are being designed to make the restauration and storage of paper items more efficient. The best approach so far is to use mixed techniques to better understand the biodeterioration. Developing new ways to guarantee the preservation of cultural heritage is a very dynamic topic and often requires interdisciplinary efforts and creativity.

\section{References}

1. Sterflinger K, Pinar G (2013) Microbial deterioration of cultural heritage and works of art-tilting at windmills?. Appl Microbiol Biotechnol 97: 9637-9646.

2. Deshmukh R, Khardenavis AA, Purohit HJ (2016) Diverse Metabolic Capacities of Fungi for Bioremediation. Indian J Microbiol 56(3): 247-264.

3. Haleem Khan AA, Mohan Karuppayil S (2012) Fungal pollution of indoor environments and its management. Saudi Journal of Biological Sciences 19(4): 405-426.

4. Mallo AC, Nitiu DS, Eliades L, Saparrat M (2017) Fungal degradation of cellulosic materials used as support for cultural heritage. International Journal of Conservation Science 8(4): 619-632.

5. Pinheiro AC, Sequeira SO, Macedo MF (2019) Fungi in archives, libraries, and museums: a review on paper conservation and human health. Critical Reviews in Microbiology 45(5-6): 686-700.

6. Carlo DE, Chisesi R, Barresi G, Barbaro S, Lombardo G, et al. (2016) Fungi and Bacteria in Indoor Cultural Heritage Environments: Microbial-related Risks for Artworks and Human Health. Environment and Ecology Research 4(5): 257-264.
7. Ettenauer JD, Jurado V, Pinar G, Miller AZ, Santner M, et al. (2014) Halophilic Microorganisms Are Responsible for the Rosy Discolouration of Saline Environments in Three Historical Buildings with Mural Paintings. PLoS one 9(8): e103844.

8. Sequeira SO, De Paiva HC, Mesquita N, Portugal A, Macedo MF (2019) Fungal stains on paper: is what you see what you get? Manchas de fungos em papel: o que se ve e o que se obtem?. Conservar patrimonio 32: 18-27.

9. Pascal Q David P, Astrid H (2013) Integrated Pest Management (IPM) in Museums, Archives and Historic Houses-Proceedings of the International Conference in Vienna, Austria 2013, pp: 1-6.

10. Sterflinger K (2010) Fungi: Their role in deterioration of cultural heritage. Fungal biology reviews 24: 47-55.

11. Kazemian N, Pakpour S, Milani AS, Klironomos J (2019) Environmental factors influencing fungal growth on gypsum boards and their structural biodeterioration: A university campus case study. PLoS one 14(8): e0220556.

12. Baloccoa C, Petronea G, Maggib O, Pasquarielloc G, Albertinid R, et al. (2016) Indoor microclimatic study for Cultural Heritage protection andpreventive conservation in the Palatina Library. Journal of Cultural Heritage 22: 956-967.

13. Ramirez JL, Santana M, Castro GI, Gonzalez A (2005) The role of biotechnology in art preservation. Trends in Biotechnology 23(12): 585-588.

14. Palla F, Brresi G (2017) Biotechnology and Conservation of Cultural Heritage. Springer.

15. Balseca N, Del Rocio L, Ordonez C, Davidc M (2016) Formulation of an antifungal solution for the treatment of books in the historical area of the Central University of Ecuador, Ecuador, pp: 1-80.

16. Cappitelli F, Sorlini C (2005) From Papyrus to Compact Disc: The Microbial Deterioration of Documentary Heritage. Critical reviews in Microbiology 31(1): 1-10. 